\title{
A novel mutation in the FOXC2 gene: a heterozygous insertion of adenosine (c.867insA) in a family with lymphoedema of lower limbs without distichiasis
}

Tanja Planinsek Rucigaj1,3, Matija Rijavec², Jovan Miljkovic ${ }^{3}$, Julij Selb², Peter Korosec ${ }^{2}$

\author{
${ }^{1}$ Dermatovenereological Clinic, University Medical Centre Ljubljana, Ljubljana, Slovenia \\ 2 University Clinic of Respiratory and Allergic Diseases Golnik, Golnik, Slovenia \\ ${ }^{3}$ Faculty of Medicine, University of Maribor, Maribor, Slovenia
}

Radiol Oncol 2017; 51(3): 363-368.

Received 26 December 2016

Accepted 23 May 2017

Correspondence to: Tanja Planinšek Ručigaj, M.D., Dermatovenerological Clinic, University Medical Center Ljubljana, Zaloška cesta 2, 1000 Ljubljana, Slovenia. E-mail: t.rucigaj@gmail.com

Disclosure: No potential conflicts of interest were disclosed.

Background. Primary lymphoedema is a rare genetic disorder characterized by swelling of different parts of the body and highly heterogenic clinical presentation. Mutations in several causative genes characterize specific forms of the disease. FOXC2 mutations are associated with lymphoedema of lower extremities, usually distichiasis and late onset.

Patients and methods. Subjects from three generations of a family with lymphoedema of lower limbs without distichiasis were searched for mutations in the FOXC2 gene.

Results. All affected family members with lymphoedema of lower limbs without distichiasis, and still asymptomatic six years old girl from the same family, carried the same previously unreported insertion of adenosine (c.867insA) in FOXC2.

Conclusions. Identification of a novel mutation in the FOXC2 gene in affected family members of three generations with lymphoedema of lower limbs without distichiasis, highlights the high phenotypic variability caused by FOXC2 mutations.

Key words: primary lymphedema; FOXC2 mutation; distichiasis; lower limbs lymphedema

\section{Introduction}

Lymphoedema, swelling due to excess accumulation of the protein-rich lymph in the tissues, is caused by inadequate lymph reabsorption or when the lymphatic vessels are absent or function defectively. ${ }^{1}$ Primary lymphoedema is affecting approximately $1.15 / 100,000$ of less than 20 years of age population. ${ }^{2}$ Affected individuals suffer from chronic lymphoedema and are at greater risk for developing infections, including bacterial infection of the skin and underlying tissue (cellulitis) or infection of the lymphatic vessels (lymphangitis). ${ }^{3}$ They are also at a greater risk than the general population for developing a malignancy, at the affected site. The most common malignancy associated with the affected area is the angiosarcoma ${ }^{4-6}$ (the condition called the Stewart-Treves syndrome), however, also other malignancies, the basal cell carcinoma, squamous cell carcinoma, melanoma, Kaposi sarcoma, Merkel cell carcinoma, and several cutaneous lymphomas ${ }^{6}$ can occur, and are probably due to the immunocompromised district of the affected area or because of the environment rich in growth factors due to the formation of collateral lymphatic vessels. ${ }^{6}$ Therefore, identification (also with the aid of genetic testing) and monitoring of patients with chronic lymphoedema (no matter the etiology) 
should be performed periodically to identify and treat malignant changes that can develop in the affected areas. ${ }^{6}$

The clinical presentation of primary lymphoedema is very variable and varies in the age of onset, the edematous part of the body affected, associated anomalies and different inheritance patterns. ${ }^{7}$ The most recent classification of primary lymphoedema has been developed as a diagnostic algorithm, proposed by Connell in $2010^{7}$ and $2013^{8}$, and is based first on different clinical presentations and second on the genetic findings.

The genetic basis of primary lymphoedema are mutations in five causative genes that also underlie specific forms of the disease ${ }^{9,10}$ namely: FLT4 (fmsrelated tyrosine kinase 4 encoding VEGFR-3 (vascular endothelial growth factor receptor 3)) mutations, that cause Milroy disease ${ }^{11-15}$; CCBE1 (collagen and calcium binding EGF domain containing protein 1) mutations that are responsible for autosomal-recessive generalized lymphatic dysplasia ${ }^{16-18}$; SOX18 (sex determining region Y-box 18) mutations that account for the hypotrichosis-lymphoedema-telangiectasia syndrome ${ }^{19} ;$ GJC2 (gap junction protein gamma 2, encoding (CX47) connexin-47) mutations which were identified in patients with four-limb lymphoedema ${ }^{20,21}$ and FOXC2 (fork head box protein C2) mutations that are responsible for autosomal dominant lymphoedema distichiasis syndrome (LDS). ${ }^{22,23}$ With the advent of the next generation sequencing technology, muta- tions in the number of new candidate genes (NRP2 (neuropilin 2), SOX17 (sex determining region Y-box 17), FABP4 (fatty acid binding protein 4), VCAM1 (vascular cell adhesion molecule 1) have been also linked to primary lymphoedema. ${ }^{10,24}$

In patients with LDS, lymphoedema of both lower limbs, that typically starts in late childhood or during puberty ${ }^{10,15}$, and varicose veins are accompanied by extra eyelashes (known as distichiasis) and also other comorbidities, such as ptosis (35\% of patients), congenital heart disease $(8 \%)$ and cleft palate $(3 \%){ }^{7,8,15}$ In the majority $(95 \%)$ of patients with LDS, mutations in the FOXC2 gene, on chromosome 16q24, are responsible for the disease (15). FOXC2 encodes a transcription factor for the signal transduction pathway ensuring normal development of the lymphatic collecting vessels and valves. ${ }^{25}$

Besides causing LDS, FOXC2 mutations have also been identified in lymphoedema without distichiasis. ${ }^{26}$ Therefore, the aim of our study was to search for causative mutations in the FOXC2 gene in three generations of a family with lymphoedema of lower limbs without distichiasis.

\section{Patients and methods}

\section{Patients}

Three family members, a 39-year-old woman, her 74-year-old father and 14-year-old son, have been

TABLE 1. Clinical findings of family members with primary lymphoedema

\begin{tabular}{|c|c|c|c|c|c|}
\hline \multicolumn{6}{|c|}{ Patients } \\
\hline Gender & $M$ & $\mathrm{~F}$ & M & $\mathrm{F}$ & $\mathrm{F}$ \\
\hline Age (years) & 74 & 39 & 14 & 9 & 6 \\
\hline Lymphoedema & Yes & Yes & Yes & No & No \\
\hline Lower limbs & Yesa & Yesa & Yesb & No & No \\
\hline Genital & Yes & No & No & No & No \\
\hline Distichiasis & No & No & No & No & No \\
\hline Onset (years) & 11 & 9 & 13 & / & / \\
\hline Varicose veins & Yes & Yes & No & No & No \\
\hline Ptosis & No & No & No & No & No \\
\hline Cleft palate & No & No & No & No & No \\
\hline Congenital heart disease & No & No & No & No & No \\
\hline FOXC2 mutation & c.867insA & c.867insA & c.867insA & No & c.867insA \\
\hline Cellulitis & Yes & Yes & No & No & No \\
\hline Yellow nails & No & No & No & No & No \\
\hline
\end{tabular}

${ }^{a}=$ whole lower limbs; ${ }^{b}=$ calves only; $F=$ female; $M=$ male 
diagnosed with primary lymphoedema at the Dermatovenerological Clinic, University Clinical Centre Ljubljana.

The 74-year-old has lymphoedema of both lower limbs stage III with fibrosis and sclerosis with only some small reticular veins present and genital edemas with lymphatic cysts. The disease started when the patient was 11 years old. The patient does not have distichiasis, ptosis, and cleft palate. There is no known history of lymphoedema in the patient's family and his wife, who had died, also did not have any history of lymphoedema. The patient has suffered a myocardial infarction in 2007 and had a mitral and a tricuspid valve replacement. Patient is being treated with short-stretch bandages and manual lymph drainage and in the maintenance phase with compression garments (bermuda shorts, and flat knitted thigh high stocking class III). Before therapy, he had suffered several erysipelas which have not reoccurred after regular therapy for lymphoedema.

The 39-years-old daughter has lymphoedema stage III of both lower limbs without genital involvement, with the disease onset at age 9. The patient, like her father, also does not have distichiasis, ptosis or cleft palate. She has varicose veins present on both of her legs. Her husband does not have lymphoedema. She is being treated with flat knitted thigh high stocking class III. Again, she had suffered several erysipelas which were stopped after regular therapy for lymphoedema. She has three children.

In her son, lymphoedema stage II of both lower limbs first occurred at the age of 13 . He has no other pathological clinical findings. He is being treated with round knitted stockings class II. He has not suffered any erysipelas.

Both her daughters aged 9 and 6 years have no symptoms and signs of lymphoedema. Age, gender, and detailed clinical characteristics of the recruited subject are presented in Table 1.

The study was approved by the Slovenian national ethics committee (number: 157/07/10) and all participants gave their informed written consent.

\section{Genetics analysis}

Genomic DNA was extracted from EDTAcontaining whole blood samples using a QIAamp DNA Blood Mini Kit (Qiagen, Hilden, Germany) according to the manufacturer's instructions. The detection of FOXC2 mutations in the $1506 \mathrm{bp}$ single exon coding region, as well as in the $5^{\prime}$ and $3^{\prime}$ regions of FOXC2 gene was performed as previously described. ${ }^{26,27}$ The primer sequence and conditions used are presented in Table 2. PCR prod-

TABLE 2. Primer sequences and conditions used to amplify and sequence the FOXC2 gene and its upstream and downstream regions

\begin{tabular}{|c|c|c|c|c|c|}
\hline Name of primer & $\begin{array}{c}\text { Sequence } \\
\left(5^{-}-3^{-}\right)\end{array}$ & $\begin{array}{l}\text { Annealing } \\
\text { temp }\left({ }^{\circ} \mathrm{C}\right)\end{array}$ & $\begin{array}{l}\text { Product } \\
\text { size (bp) }\end{array}$ & DMSO \% & $\mathrm{MgCl} 2 \mathrm{mM}$ \\
\hline $\mathrm{FOXC2}-1 \mathrm{Fa}$ & TCTGGCTCTCTCGCGCTCT & \multirow{2}{*}{58} & \multirow{2}{*}{476} & \multirow{2}{*}{6} & \multirow{2}{*}{1.5} \\
\hline FKHLI 14-2R & AGTAACTGCCCTTGCCGG & & & & \\
\hline $\mathrm{FOXC2}-2 \mathrm{~F}^{\mathrm{a}}$ & ACCGCTTCCCCTTCTACCGG & \multirow{2}{*}{60} & \multirow{2}{*}{519} & \multirow{2}{*}{10} & \multirow{2}{*}{1.5} \\
\hline FOXC2-2R & TCATGATGTTCTCCACGCTGAA & & & & \\
\hline FKHL 14-4F a & GAAGGTGGTGATCAAGAGCG & \multirow{2}{*}{60} & \multirow{2}{*}{496} & \multirow{2}{*}{6} & \multirow{2}{*}{1.5} \\
\hline FOXC2-3R & GAGGTTGAGAGCGCTCAGGG & & & & \\
\hline $\mathrm{FOXC2}-4 \mathrm{~F}$ a & CTGGACGAGGCCCTCTCGGAC & \multirow{2}{*}{61} & \multirow{2}{*}{464} & \multirow{2}{*}{10} & \multirow{2}{*}{1.5} \\
\hline FOXC2-4R & GGAGGTCCCGGGACACGTCA & & & & \\
\hline FOX_5P_1Fb & GCCGACGGATTCCTGCGCTC & \multirow{2}{*}{61} & \multirow{2}{*}{378} & \multirow{2}{*}{10} & \multirow{2}{*}{1.5} \\
\hline FOX_5P_IR & CCGCTCCTCGCTGGCTCCA & & & & \\
\hline FOX_5P_2F b & CCGATTCGCTGGGGGCTTGGAG & \multirow{2}{*}{61} & \multirow{2}{*}{607} & \multirow{2}{*}{6} & \multirow{2}{*}{1.5} \\
\hline FOX_5P_2R & GCGGGCTGGTGGTGGTGGTAGG & & & & \\
\hline FOX_3P_IFb & CAACGTGCGGGAGATGTTCAAC & \multirow{2}{*}{61} & \multirow{2}{*}{464} & \multirow{2}{*}{10} & \multirow{2}{*}{1.5} \\
\hline FOX_3P_IR & CACAGCACAGCCGTCCTGGTAG & & & & \\
\hline FOX_3P_2F c & TACTGACGTGTCCCGGGACC & \multirow{2}{*}{61} & \multirow{2}{*}{468} & \multirow{2}{*}{6} & \multirow{2}{*}{1.5} \\
\hline FOX_3P_2R & CCACACATTTGTACAGCACGGTTG & & & & \\
\hline
\end{tabular}

$a=$ Primer pairs from ${ }^{27} ;{ }^{b}=$ Primer pairs from ${ }^{28} ; c=$ Primer pairs from ${ }^{26}$ 


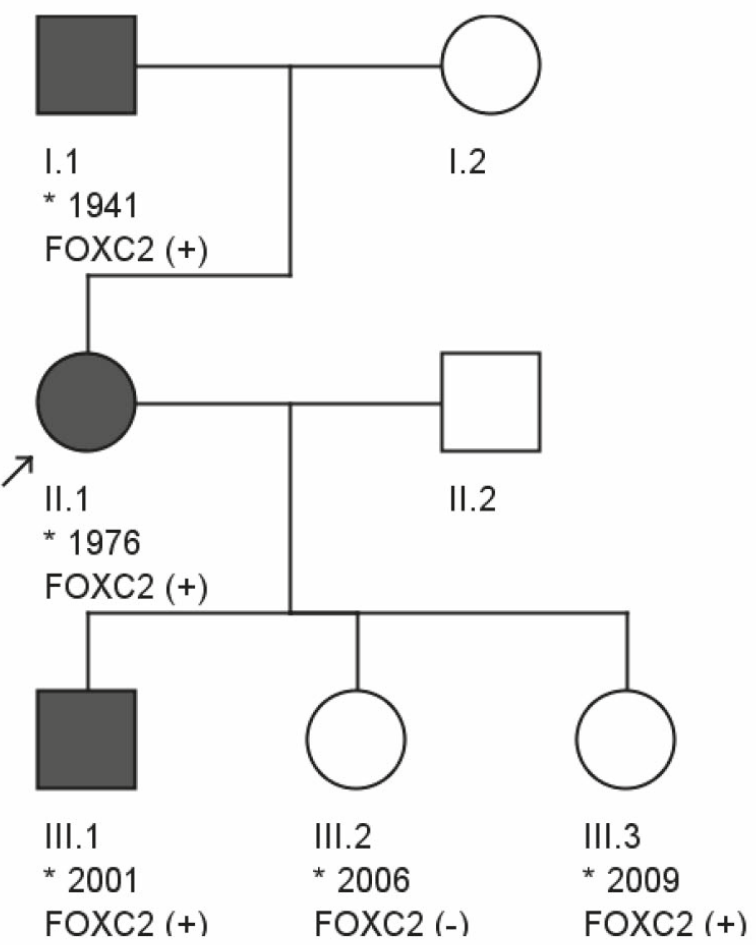

FIGURE 1. Pedigree of the family with new mutation in FOXC2 gene. Full symbols indicate patients with lymphoedema, asterisk $(*)$ indicate year of birth of the recruited subjects and subjects with c.867insA FOXC2 mutation are indicated as FOXC2 (+).

ucts were sequenced using Big Dye Terminator kit (Thermo Fisher Scientific) and 3730xl DNA analyzer (Thermo Fisher Scientific). To identify mutations, sequences were compared with the FOXC2 reference sequence in the GenBank (GenBank accession number NG_012025.1) using the SeqScape Software v2.6 (Thermo Fisher Scientific). Mutations numbering is based on cDNA sequence, where the first nucleotide (A) of the initiation codon (ATG) is considered nucleotide number one.

\section{Results}

\section{Clinical details}

The clinical detail of all five patients are shown in Table 1.

\section{Genetics analysis}

In all affected members of the described three generation family with lymphoedema of lower limbs without distichiasis the same mutation in FOXC2 responsible for the disease was identified (Figure 1). The mutation identified in our patients is a heterozygous insertion of adenosine (c.867insA) and was not previously described. This insertion was present in three family members affected by primary lymphoedema, as well as in a six years old girl without any symptoms and signs of lymphoedema at the time of analysis, while it was absent in a healthy nine years old girl.

Since the discovered mutation was not previously reported we additionally evaluated this mutation in 182 normal controls. None of the controls harbored the mutation, which further supports the causative nature of the mutation.

\section{Discussion}

Up to date only one lymphedema family with FOXC2 mutation without any individual with distichiasis was found. ${ }^{26}$ We report the second family of three generations with FOXC2 mutation and in which all affected individuals demonstrated lymphedema without distichiasis. Molecular analysis helped to identify the causative heterozygous insertion of adenosine (c.867insA) in the FOXC2 gene, which was previously not described. This mutation causes frameshift and premature termination of the mature protein since stop codon is inserted behind amino acid 461, leading to a truncation of the mature protein and consequently to the elimination of key alpha-helical domains required for the transcription process. ${ }^{26}$ Frameshift mutations are expected to alter the reading frame or lead to a premature termination of the protein, and as a result those unstable mRNA transcripts are removed through the nonsense-mediated $\mathrm{mR}$ NA decay pathway. ${ }^{28,29}$ The causative nature of the identified variant was further supported by the fact that the mutation was not found in any of the 182 tested normal controls.

In all three patients of our family, lymphoedema developed between the age of 9 and 13. The onset of lymphoedema in literature is typically during puberty or in late childhood. ${ }^{7,26,30}$ In the 6 years old girl without clinical manifestations of lymphoedema with mutation in FOXC2, lymphoedema will very likely develop within the next few years. She also has no other clinical findings that were described in patients with FOXC2 mutations. All three patients have lymphoedema of both lower limbs like the patients described in the literature. ${ }^{14,28}$ Because of delayed therapy with compression in the female patient and her father, lymphoedema of the legs is in the III ${ }^{\text {rd }}$ stage. Patient's father also has lymphoedema of genital region with oc- 
casional lymphorrhea. Several papers have mentioned that lymphoscintigraphy, because of valve failure, indicate distal lymph reflux in patients with LDS. ${ }^{6,29,31}$ In our two older patients not only early therapy, but also lymphoscintigraphy have been performed in other institutions abroad, and thus unfortunately any information about those findings are not available. Also for the young boy, his mother did not allow to perform early diagnostic procedures, because of known family diagnosis. Both, the patient and her father had suffered many erysipelas before therapy. After regular wearing of compression garments erysipelas were stopped. The son started with compression stockings class II immediately after the onset of edema. He has lymphoedema stage II with morning swelling, without sequelae. Our female patient and her father both have reticular varicose veins without reflux. In the literature lymphoedema and varicose veins are accompanied by distichiasis, which occur in $94.3 \%$ of the patients with mutations in the FOXC2 gene. ${ }^{15,32}$ Affected individuals can also have ptosis (in 35\% of patients), congenital heart disease ( $8 \%$ ), clef palate $(3 \%)$ and in some patients yellow nails and cystic hygromas have been described. ${ }^{26}$ In our patients there were no distichiasis, no cleft palate, no ptosis or yellow nails, no congenital heart defects or cystic hygromas.

Mutations in the FOXC2 appear to be the primary cause of LDS. However, not only that some features of the LDS phenotype can be found in patients without FOXC2 mutations ${ }^{26}$ our study and also previous report ${ }^{26}$ obviously suggest that mutations in the FOXC2 gene can be found in lymphoedema patients without distichiasis.

The FOXC2 gene encodes for a forkhead transcription factor implicated in the development of lymphatic and vascular system, particularly affecting the function of the valves. ${ }^{25,32}$ The role has been implicated from animal models where it is expressed in developing mesenchymal cells which develop into blood and lymphatic vessels. Moreover, homozygous null mice (foxc2-/-) have non-functioning blood vessels. ${ }^{25,32}$ In humans FOXC2 mutations were associated with primary valve failure and venous reflux, indicating its requirement for proper venous function. ${ }^{15,25,32}$ Mutations in FOXC2 most often cause LDS, with lymphoedema of lower extremities, distichiasis, and the disease onset usually after puberty. ${ }^{7,8,10,15,26,32-35}$ However, the penetrance and disease expression seems to be highly variable. This was also confirmed by our family in which none of the patients with the novel FOXC2 mutation had distichiasis.

\section{Conclusions}

In conclusion, we identified a causative previously unreported insertion in FOXC2 in affected members of three generation family with lymphoedema of lower limbs without distichiasis, highlighting the high heterogeneity of phenotypic variability caused by FOXC2 mutations.

\section{References}

1. Planinsek Rucigaj T, Tlaker Zunter V. Lymphedema: clinical picture, diagnosis and management. In: Singh N, editor. Radioisotopes - applications in biomedical science. InTech; 2011. Available from: https://www.intechopen. com/books/radioisotopes-applications-in-bio-medical-science/lymphedema-clinical-picture-diagnosis-and-management. doi:10.5772/24515

2. Smeltzer DM, Stickler GB, Schirger A. Primary lymphedema in children and adolescents: a follow-up study and review. Pediatrics 1985: 76: 206-18.

3. Al-Niaimi F, Cox N. Cellulitis in lymphoedema: a vicious cycle. J Lymph 2009; 42: 38-42.

4. Sharma A, Schwartz RA. Stewart-Treves syndrome: pathogenesis and management. J Am Acad Dermatol 2012; 67: 1342-8. doi:10.1016/j. jaad.2012.04.028

5. Dürr HR, Pellengahr C, Nerlich A, Baur A, Maier M, Jansson V. Stewart-Treves syndrome as a rare complication of a hereditary lymphedema. Vasa 2004; 33: 42-5. doi:10.1024/0301-1526.33.\$65.42

6. Lee R, Saardi KM, Schwartz RA. Lymphedema-related angiogenic tumors and other malignancies. Clin Dermatol 2014; 32: 616-20. doi:10.1016/j. clindermatol.2014.04.008

7. Connell F, Brice G, Jeffery S, Keeley V, Mortimer P, Mansour S. A new classification system for primary lymphatic dysplasias based on phenotype. Clin Genet 2010; 77: 438-52. doi:10.1111/cge.12173

8. Connell F, Gordon K, Brice G, Keely V, Jeffrea S, Mortimer P, et al. The classification and diagnostic algorithm for primary lymphatic dysplasia: an update from 2010 to include molecular findings. Clin Genet 2013; 84: 303-14.

9. Ostergaard $P$, Simpson MA, Jeffery $S$. Massively parallel sequencing and the identification of genes for primary lymphoedema: a perfect fit. Clin Genet 2011; 80: 110-6. doi:10.1111/j.1399-0004.2011.01706.x

10. Mendola A, Schlögel MJ, Ghalamkarpour A, Irrthum A, Nguyen HL, Fastré E, et al. Mutations in the VEGFR3 signaling pathway explain $36 \%$ of familial lymphedema. Mol Syndromol 2013; 4: 257-66. doi:10.1159/000354097

11. Ferrell RE, Levinson KL, Esman JH, Kimak MA, Lawrence EC, Barmada NM, et al. Hereditary lymphedema: evidence for linkage and genetic heterogeneity. Hum Mol Genet 1998; 7: 2073-8.

12. Evans AL, Brice G, Sotirova V, Mortimer P, Beninson J, Burnard K, et al. Mapping of primary congenital lymphedema to the $5 q 35.3$ region. Am J Hum Genet 1999; 64: 547-55. doi:10.1086/302248

13. Karkkainen MJ, Ferrell RE, Lawrence EC, Kimak MA, Levinson KL, McTique $\mathrm{MA}$, et al. Missense mutations interfere with VEGFR-3 signalling in primary lymphoedema. Nat Genet 2000; 25: 153-9. doi:10.1038/75997

14. Irrthum A, Karkkainen MJ, Devriendt K, Alitalo K, Vikkula M. Congenital hereditary lymphedema caused by a mutation that inactivates VEGFR3 tyrosine kinase. Am J Hum Genet 2000; 67: 295-301. doi:10.1086/303019

15. Brice G, Mansour S, Bell R, Collin JR, Child AH, Brady AF, et al. Analysis of the phenotypic abnormalities in lymphoedema distichiasis syndrome in 74 patients with FOXC2 mutations or linkage to 16q24. J Med Genet 2002; 39: 478-83. doi:10.1136/jmg.39.7.478

16. Hennekam RCM, Geerdink RA, Hamel BCJ, Hennekam FA, Kraus P, et al. Autosomal recessive intestinal lymphangiectasia and lymphedema, with facial anomalies and mental retardation. Am J Med Genet 1989; 34: 593600. doi:10.1002/ajmg.1320340429 
17. Alders M, Hogan BM, Gjini E, Salehi F, Al-Gazali L, Hennekam EA, et al. Mutations in CCBE1 cause generalized lymph vessel dysplasia in humans. Nat Genet 2009; 41: 1272-4. doi:10.1038/ng.484

18. Alders M, Mendola A, Ades L, Al Gazali L, Bellini C, Dallapicola B, et al. Evaluation of clinical manifestations in patients with severe lymphedema with and without CCBE1 mutations. Mol Syndromol 2013; 4: 107-13. doi:10.1159/000342486

19. Irrthum A, Devriendt K, Chitayat D, Matthijs G, Glade C, Steijlen PM, et al. Mutations in the transcription factor gene SOX18 underlie recessive and dominant forms of hypotrichosis-lymphedema-telangiectasia. Am J Hum Genet 2003; 72: 1470-8. doi:10.1086/375614

20. Ferrell RE, Baty CJ, Kimak Ma, Karlsson JM, Lawerence EC, Franke-Snyder $\mathrm{M}$, et al. GJC2 missense mutations cause human lymphedema. Am J Hum Genet 2010; 86: 943-8. doi:10.1016/j.ajhg.2010.04.010

21. Ostergaard P, Simpson MA, Brice G, Mansour S, Connell FC, Onaoufridais A, et al. Rapid identification of mutations in GJC2 in primary lymphoedema using whole exome sequencing combined with linkage analysis with delineation of the phenotype. J Med Genet 2011; 48: 251-5. doi:10.1136/ jmg.2010.085563

22. Fang J, Dagenais SL, Erickson RP, Arlt MF, Glynn MW, Gorski JL, et al. Mutations in FOXC2 (MFH-1), a forkhead family transcription factor, are responsible for the hereditary lymphedema-distichiasis syndrome. Am J Hum Genet 2000; 67: 1382-8. doi:10.1086/316915

23. Shimoda $\mathrm{H}$, Bernas MJ, Witte MH. Dysmorphogenesis of lymph nodes in Foxc2 haploinsufficient mice. Histochem Cell Biol 2011; 135: 603-13. doi:10.1007/s00418-011-0819-x

24. Ferrell RE, Kimak MA, Lawrence EC, Finegold DN. Candidate gene analysis in primary lymphedema. Lymphat Res Biol 2008; 6: 69-76. doi:10.1089/ Irb.2007.1022

25. Bell R, Brice G, Child AH, Murday VA, Mansour S, Sandy CJ, et al. Analysis of lymphoedema-distichiasis families for FOXC « mutations reveals small insertions and deletions throughout the gene. Hum Genet 2001; 108: 546-51.

26. Finegold DN, Kimak MA, Lawrence EC, Levinson KL, Cherniske EM, Pober $\mathrm{BR}$, et al. Truncating mutations in FOXC2 cause multiple lymphedema syndromes. Hum Mol Genet 2001; 10: 1185-9.

27. Kovacs P, Lehn-stefan A, Stumvoll M, Bogardus C, Baier L. Genetic variation in the human winged helix/forkhead transcription factor gene FOXC2 in Pima Indians. Diabetes 2003; 52: 1292-5. doi:10.2337/diabetes.52.5.1292

28. Frischmeyer PA, van Hoof A, O’Donnell K, Guerrerio AL, Parker R, Dietz HC An mRNA surveillance mechanism that eliminates transcripts lacking termination codons. Science 2002; 295: 2258-61. doi:10.1126/science.1067338

29. Van Steensel MA, Damstra RJ, Heitink M, Bladergroen RS, Veraart J, Steijlen $\mathrm{PM}$, et al. al. Novel missense mutations in the FOXC2 gene alter transcriptional activity. Hum Mutat 2009; 30: E1002-9. doi:10.1002/humu.21127

30. Burnand KG, Mortimer PS. Lymphangiogenesis and genesis of lymphedema. In: Browse N, Burnand KG, Mortimer PS, editors. Diseases of the lymphatics. London: Arnold; 2003. p. 102-9.

31. Sholto-Douglas-Vernon C, Bell R, Brice G, Mansur S, Satfarazi M, Child AH, et al. Lymphoedema distichiasis and FOXC2: unreported mutations, de novo mutation estimate, families without coding mutations. Hum Genet 2005; 117: 238-42. doi:10.1007/s00439-005-1275-2

32. Mellor RH, Brice G, Stanton AW, French J, Fernch J, Smith A, et al. Mutations in FOXC2 are strongly associated with primary valve failure in veins of the lower limb. Circulation 2007; 115: 1912-20. doi:10.1161/ CIRCULATIONAHA.106.675348

33. Sutkowska E, Gil J, Stembalska A, Hill-Bator A, Szuba A. Novel mutation in the FOXC2 gene in three generations of a family with lymphoedema-distichiasis syndrome. Gene 2012; 498: 96-9. doi:10.1016/j.gene.2012.01.098

34. Rosbotham JL, Brice GW, Child AH, Nunan TO, Mortimer PS, Burnand KG. Distichiasis-lymphoedema: clinical features, venous function and lymphoscintigraphy. Br J Dermatol 2000; 142: 148-52. doi:10.1046/j.1365 2133.2000.03258.x

35. Petrova TV, Karpanen T, Norrm'en C, Mellor R, Tamakoshi T, Finegold D, et al. Defective valves and abnormal mural cell recruitment underlie lymphatic vascular failure in lymphedema distichiasis. Nat Med 2004: 10: 974-81. doi:10.1038/nm1094 